te relevante (se faça uma afirmação de direito), para que se concretize o fundamento necessário do pedido.

A cuidadosa análise dos requisitos que impōe a lei à petição inicial conforta tal orientação, mormente quando se lê o disposto nos art. 282, III, do CPC:

A petição indicará:

III - o fato e os fundamentos jurídicos do pedido...

A exigência mais severa quanto aos requisitos da petição inicial e, mais do que isso, quanto à vinculação entre o pedido $e$ a causa de pedir, por certo evitaria o desenvolvimento de processo que deveriam ter sido abortados em seu início. A tentativa que se faz, na melhor das intenções (evitar prejuízos às partes autoras), de "interpretar" ações mal propostas, conduz, mais das vezes, além do imenso dano que causam a defesa, a feitos tumultuados e de difícil solução, o que, sempre que possível, há de ser evitado.

\section{Notas}

1 ...La demanda por lo general pone en marcha el processo, y es por ello el acto más importante de la parte; pero además delimita el objeto litigioso $y$ en consecuencia es también de gran significación para el más importnte acto judicial: la sentencia... (pg. 150)

2 Há comunicação de vontade (e declaração é da classe das declaraçōes dependentes de recep̧ão); mas o que prima é a declaração, base da relação jurídica processual...

${ }^{3}$ La demanda és en si misma, una comnicación al Jues, del conflicto de intereses, que va dar lugar al proceso... (p. 29) 40 autor não pode limitar-se a submeter ao juiz um conjunto de fatos e deixar ao seu discernimento as consequiências jurídicas que queira extrair deles; ao contrário, o autor tem a seu encargo a indicação do objeto e o fundamento da pretensão proposta e a apresentação de uma petição determinada...

${ }^{5}$ La demanda es el conjunto de la exposición que se formula al juez. La petición es sólo una de las partes de ese conjunto..

\title{
Responsabilidade pela sucumbência no Código de Processo Civil
}

\section{Ovídio A. Batista da Silva}

Professor Titular de Direito Processual Civil da Faculdade de Direito UFRGS.

1. Nosso vigente Código de Processo $\mathrm{Ci}$ vil, como se sabe, estabeleceu disciplina diversa, no que respeita à responsabilidade pelos encargos da sucumbência, daquela que lhe dava o Código revogado. Enquanto o estatuto de 1939 somente previa a condenação do vencido a reembolsar ao vencedor as custas do processo e os honorários que este tivesse dispendido com seu advogado, quando o sucumbente se houvesse comportado de modo temerário ou praticado abuso do direito (arts. $3^{\circ}$ e 63), o Código em vigor atribui ao sucumbente, invariavelmente, $O$ ônus de ressarcir ao vencedor as despesas que este tiver feito, no processo, inclusive honorários de advogado. No sistema do Código, o fato da sucumbência, por si só, determina a responsabilidade do vencido pelas despesas processuais feitas pelo vencedor. Trata-se, como a doutrina o considera, um caso de responsabilidade objetiva.

A redação do art. 20 do estatuto em vigor confirma o princípio, ao dispor: "A sentença condenará o vencido a pagar ao vencedo as despesas que antecipou e os honorários de advogado". A sucumbência determina a obrigação de ressarcir ao vencedor as despesas, inclusive honorários de advogado, que o vencedor porventura haja realizado no processo.

2. Costuma-se atribuir à Chiovenda paterninade da solução adotada por nosso Código. Isto parece, até certo ponto, correto. Embora não se possa creditar-lhe a au toria deste princípio, que deita raízes históricas mais profundas, é certo que a lição do mestre italiano exerceu influência decisiva na doutrina e nas codificações modernas. Esta lição de Chiovenda transcrita pelo professor Celso Barbi (Comentários ao Código de Processo Civil, vol. I, Tomo I, 1975, pág. 187) confirma o que se disse. Procurando fundamentar o princípio da condenação do vencido a ressarcir ao vencedor as despesas da causa, escreve o jurista peninsular: "O fundamento dessa condenação é o fato objetivo da derrota; e a justificação desse instituto está em que a atuação da lei não deve representar uma diminuição patrimonial para a parte a cujo favor se efetiva; por ser interesse do Estado que o emprego do processo não se resolva em prejuízo de quem tem razão, e por ser, de outro turno, interesse do comércio jurídico que os direitos tenham um valor tanto quanto possível nítido e constante" (Instituições de direito processo civil, $2^{\underline{a}}$ edição da tradução brasileira, 1965, 3o vol., pág. 207).

3. De nosso ponto de vista, porém, duas ordens de objeções podem ser levantadas contra o modo como o Código disciplinou a responsabilidade pelas despesas processuais. A primeira delas diz respeito à rigidez com que o princípio da denominada responsabilidade objetiva foi estabelecido. Se ria recomendável que a lei fosse mais flexível, ao tratar desta matéria, de modo que o princípio desse oportunidade a um tratamento diferenciado e mais liberal em determinadas circunstâncias com que a prática forense seguidamente se depara.

Não são raros os casos em que a atribuição ao vencido da responsabilidade pelas despesas feitas pelo vencedor, resulta em

R. Fac. Direito UFRGS, Porto Alegre, 9(1): 227-233, nov. 1993 
solução injusta. E mesmo sabendo-se que a escolha do critério da responsabilidade objetiva - por isso que objetiva a responsabilidade -, não leva em conta a existência de culpa para obrigar o vencido a restituir ao vencedor o que este houver desembolsado com sua atuação no processo; ainda assim a injustiça flagrante que possa resultar da aplicação do princípio, em certos casos concretos, provoca um estado de insatisfação e até mesmo de revolta contra a ausência de qualquer margem de plasticidade com que o aplicador da lei poderia temperar o sistema, de modo a adaptá-lo às circunstâncias especiais de certas hipóteses.

Pense-se em alguns exemplos que podem ilustrar esta primeira objeção. $\mathrm{Na}$ ação de consignação em pagamento, poderá ocorrer que o credor tenha recusado a oferta de pagamento por considerá-la insuficiente, tendo o devedor, na ação consignatória, complementado o pagamento, como the permite o art. 899 do CPC, admitindo, por tal modo, a procedência, neste ponto, da contestação.

Neste caso, a ação será julgada procedente, porém a contestação, onde se alegara a insuficiência do depósito originariamente feito na ação, não era menos procedente. $O$ credor demandado, embora tivesse razão para opor-se à pretensão inicialmente articulada pelo autor da consignatória, resultará sucumbente, e apenas por força da sucumbência condenado a ressarcir ao vencedor as despesas, mesmo que este tenha sido, como no caso efetivamente o fora, o litigante a dar causa ao processo, em virtude de sua conduta equivocada e culposa.

4. Outro exemplo onde o princípio consagrado pelo art. 20 não oferece solução satisfatória, dá-se nos casos em que o juiz, ao julgar procedente a ação, leva em conta algum fato superveniente (art. 462). Neste caso também a resistência oposta pelo demandado, ao contestar a ação, fora legítima e a defesa somente não veio a ser acolhida na sentença em virtude justamente da ocorrência do fato superveniente, que acabou por livrar o autor de ver a demanda rejeitada.
Nestes casos, a necessidade de ir a juízo para obter a satisfação do direito não decorrera de uma resistência injustificada do demandado e nem poderá dizer-se que ele tivesse dado causa ao processo, em razão de um comportamento ilegítimo. Ao contrário, fora o próprio autor o responsável direto pelo ajuizamento da ação. Parece justo que se lhe atribua a responsabilidade pelas despesas da causa, inclusive pelos honorários pagos pelo réu a seu advogado, mesmo que este resulte sucumbente.

5. Ao referirmo-nos à circunstância de não ter, nas hipóteses figuradas, dado causa ao processo, alcançamos o segundo reparo que nos parece deva ser feito ao sistema adotado pelo Código. Com efeito, o outro princípio norteador da responsabilidade pelas despesas da causa, baseado na culpa, é conhecido como o princípio da causalidade. Segundo este sistema, o litigante somente suportará o pagamento das despesas processuais feitas pelo adversário quando houver dado causa à demanda, em virtude de alguma forma de comportamento injustificado, antes da propositura da ação, ou no curso do processo.

6. Enquanto, para a primeira solução leva-se em conta apenas a sucumbência como fator determinante da obrigação de indenizar o vencedor, o outro sistema parte do princípio de que, sendo a jurisdição um serviço público como qualquer outro, aqueles que o procuram deverão arcar com as despesas correspondentes, a não ser nos casos em que o sucumbente tenha agido com dolo ou culpa, ou tenha-se comportado temerariamente no curso da causa, de modo que se deva reconhecer em sua conduta al gum tipo de abuso do direito de demandar.

A não ser nestes casos excepcionais, as despesas provocadas pelo processo haverão de ser repartidas por ambos os contendores, de modo que cada um deles suporte o respectivo pagamento, especialmente o pagamento dos honorários devido a seu advogado.

7. O sistema adotado pelo Código tem seu fundamento resumido neste argumento exposto por Chiovenda: "Tendo em conta que a atividade do Estado, para operar a atuação da lei, exige tempo e despesa, urge impedir que aquele que se viu na necessidade de servir-se do processo para obter razão, tenha prejuízo do tempo e da despesa exigidos; a necessidade de servir-se do processo para obter razão não deve reverter em dano a quem tem razão" (Instituições, $1^{\circ}$ vol., pág. 207).

A quem considere os dois sistemas sem se deter no exame de seus verdadeiros pressupostos, parecerá que ambos divergem entre si em pontos tão essenciais que se poderia dizer serem cada um deles o oposto do outro. Contudo, se detivermo-nos na análise de seus fundamentos, logo veremos que o sistema da responsabilidade objetiva, ao atribuir ao vencido o ônus de suportar as despesas do vencedor, baseia-se, como o outro, no pressuposto de que o sucumbente perdera a demanda por não ter razão e, em tais circunstâncias, por haver resistido injustificadamente à pretensão exercida pelo demandante. E nisto que reside a essência $\mathrm{da}$ doutrina defendida por Chiovenda, quando ele assevera que o emprego do processo não deverá resultar em prejuízo de quem tem razão. Supõe-se, no plano do direito material, que alguém tenha razão $e$ que o sucumbente, resistindo ao cumprimento da obrigação, agira culposamente.

Sem levar em conta o compromisso, que parece bem visível, desse sistema com a denominada "teoria concreta" do direito de ação, posto que sua formulação leva em conta exclusivamente a situação do auto vitorioso - que acaba identificado com o credor verdadeiro -, os argumentos servem para justificar a atribuição da responsabilidade pelas despesas ao autor, quando a demanda seja rejeitada. Também neste caso, no fato da sucumbência está-se a ver a culpa de quem se servira do processo sem ter razão; logo, de quem resistira, ou exigira, culposamente, do adversário vitorioso algo que a lei não lhe atribuia.

8. O princípio que dá vida ao sistema da responsabilidade objetiva - ao proclamar que "a necessidade de servir-se do processo para obter razão não deve reverter em dano a quem tem razão", (Chiovenda) -, assenta-sé na suposição de que, no plano das relações jurídicas em geral, fora do processo, alguém tenha razão, quer dizer tenha direitos subjetivos e pretensões tão claros e indiscutíveis, que o futuro sucumbente, ao negá-los, estará comportando-se injustamente, ou desenvolvendo conduta antijurídica e portanto ilegítima.

$\mathrm{O}$ que o sistema da responsabilidade objetiva tem como pressuposto é o fato de haver direitos subjetivos e pretensões tão claramente assentados na lei que toda a resistência porventura oposta pelo futuro sucumbente será injustificada, legitimando que ele suporte os encargos processuais.

Pajardi, um jurista que tem-se dedicado ao estudo deste tema, aderindo a uma decisão tomada por uma corte italiana, escreve: "Il rimborso delle spese processuali serve a reintegrare il patrimonio di una delle parti che ha risentito pregiudizio economico dal costo di una lite. La causa di tale pregiudizio è nel comportamento antigiurídico (grifado por nós) di colui che costringe alla instaurazione del processo per la tutela del diritto disconosciuto o violato; antigiuricità che concreta una responsabilità di natura aquiliana, manifestandosi como violazione del generico precetto del neminem laedere (Piero Pajardi, La responsabilità per spese e i danni del processo - Appendice di aggionnamento, 1964, pág. 2)

E o mesmo autor, ao referir-se à doutrina da resposabilidade objetiva, afirma que o pressuposto da antijuridicidade da conduta do sucumbente "era inconsciamente anche nel pensiero di chi ha sostenuto la tesi opposta" àquela por ele defendida, qual seja a da causalidade (ob. e loc. cits.). Daí dizer Pajardi que "il vero fondamento della responsabilità in questione è il principio della causalità".

O Tribunal de Milão, segundo o jurista, fez uma aplicação do princípio da causalidade ao estabelecer esta máxima: "La soccombenza e la conseguente condanna alle spese pressuppongono sempre un rapporto 
di causalità fra il comportamento antigiuridico del condannato e le spese; occore cioè che il comportamento antigiuridico di lui abbia reso necessari il processo e la sua prosecuzione e, quindi, le relative spese" (pág. 3).

Foi justamente com base no princípio da causalidade que o Tribunal, apreciando um os fundamentos de uma ação de cobrança, prosseguiu dizendo: "...pertanto, il creditore che abbia rifiutato la offerta non formale della prestazione dovuta può ottenere in giudizio, ma a sue spese, la condanna del debitore alla prestazione". Não basta, diz Pajardi, o fato da sucumbência para justificar dogmaticamente a responsabilidade pelas despesas processuais. Esta conseqüência, afirma ele, "richiama la necessità di esaminare il comportamento preprocessuale della parte soccombente per un giusto regolamento delle spese processuali".

Gualandi, outro jurista interessado neste mesmo tema, comentando uma decisão da Pretoria de Bolonha, ao comparar os dois sistemas, o da causalidade e o da responsabilidade objetiva, escreve o seguinte: "...nè dovrebbero avere più senso, a nostro avviso, le polemiche diretta a stabilire la prevalenza del criterio della cuasalità o quello della soccombenza, contrapponendo l'un principio all'altro, una volta che si tenga ben fermo il fatto che la soccombenza non è che il più frequente modo di riverlarsi o di estrinsecarsi del principio di causalità nel processo di cognizione" (Angelo Gualandi, Rivista di diritto processuale, 1958, pág. 652).

Defendendo posições análogas, encontram-se Eduardo Grasso (Commentario del Codice di Procedura Civile, coordenado por Allorio, 1o vol., 1973, pág. 984); e anteriormente Virgilio Andreoli (Commentario al Co dice di Procedura Civile, $1^{\circ}$ vol., 1961, pág 256), mostrando este último, aliás, que $\mathrm{Me}$ nestrina e o próprio Chiovenda não pressupunham a consagração extremada do princípio da pura sucumbência como critério exclusivo para atribuição da responsabilidade pelas despesas da causa.
9. Poder-se-ia dizer, com efeito, comparando os dois sistemas, que o da causalidade atribui a responsabilidade pelas despesas ao litigante que se tenha mostrado culpado pela propositura da ação ou, por qualquer modo, tornado necessária a invocação da tutela jurisdicional, por haver desconhecido o direito do litigante vitorioso; ao passo que o sistema da responsabilidade objetiva, ao prescindir da existência da culpa in concreto, na verdade dela não prescinde, mas simplesmente a presume juris et de juris.

$\mathrm{O}$ entendimento de Carnelutti (Sistema di diritto processuale civile, $1^{\circ}$ vol., $1936, \mathrm{n}^{\circ}$ 171) não se distancia muito dessa linha de argumentos ao escrever:

"Ciò vuol dire che la responsabilità della parte per le spese è una responsabilità obbiettiva. Tale non era in principio; nel processo romano classico e anche, per lungo tempo, nella extraordinaria cognitio, il pressupposto della responsabilità era la temeritas e cosi la colpa del litigante; ma poi, il costo del processo man mano accresciuto $e$, d'altra parte, la difficoltà di accertare la colpa del soccombente (grifado por nós) fecero sentire il bisogno di un freno alla iniziativa dei litiganti più energico che non sia la responsabilità subbiettiva. Appunto perchè il processo è un ordigno necessario ma pericoloso, il quale non si manneggia senza ledere l'interesse altrui, e cosi, in primo luogo, senza determinare delle spese, si vuole che chi le cagiona ne sopporti il carico. La radice della responsabilità sta dunque nella relazione causale tra il danno e la attività di un uomo".

Dizendo-se simplesmente relação de causalidade entre atividade e dano, como pressuposto do dever de ressarcir as despesas processuais, poderíamos ser induzidos a supor que o elemento subjetivo estaria inteiramente afastado do sistema da responsabilidade objetiva. Entretanto, como disse Carnelutti, a opção por este critério teve em mira apenas superar as dificuldades de comprovar, em cada caso concreto, o pressuposto da culpabilidade do sucumbente a qual, sendo assim, está presumida pela lei.
Com efeito, ao aludir aos dispositivos da lei italiana que procuram abrandar o rigor da responsabilidade decorrente exclusivamente da sucumbência, prossegue Carnelutti: "...tali ragioni riguardano per lo più la sua buona fede (grifamos) nel proporre la domanda, cioè la sua meditata opinione di aver ragione onde la compensazione delle spese apparisce come una attenuazione della responsabilità del soccombente complementare a quell'aggravamento, che ha per pressupposto, invece, la lite temeraria" (pág. 445).

10. Qual dentre os dois o melhor sistema; ou qual dos dois o mais perfeito? Se aceitarmos a posição assumida pela ciência processual, submetendo-nos à lógica e aos princípio peculiares às ciências empíricas, em sua constante, e necessária, busca das generalidades em que se traduzem as leis científicas, então poderemos dizer que o sistema da responsabilidade objetiva é "cientificamente" mais perfeito, por ter superado o "casuismo" que tanto desagrado causa aos téoricos de processo civil, alcançando o valor de um princípio geral, com pretensão de validade universal que, como tal, prescinde dos fatos, ao dispensar a prova da culpa in concreto.

Porém, se quisermos, ao contrário, resgatar a idéia do Direito como tentativa de realização prática da justiça, então teríamos de pôr em dúvida o sistema da responsabilidade objetiva precisamente, porque, ao generalizar o pressuposto da culpa, ou da causalidade - dando-lhe a força de uma presunção absoluta -, o sistema acaba adotando uma posição maniqueísta, segundo a qual o vencido teria sempre resistido de má fé à pretensão do vencedor.

Ora, aos juristas dedicados ao foro, soa como uma tosca heresia a suposição de que o vencido na causa tenha obrigado o vencedor a valer-se do processo em virtude de um comportamento culposo, ou por temeridade ou má fé.

A idéia que em geral a doutrina sugere, e que fica bem visível no modo como Código trata da responsabilidade pelas des- pesas processuais - fruto indiscutível de uma visão iluminista do direito -, é a de que os direitos consagrados pelo ordenamento jurídico sejam tão claros e evidentes que somente a má fé ou o abuso do direito, traduzidos numa conduta temerária e injustificada resistência a seu cumprimento poderiam explicar a necessidade do ajuizamento da demanda.

Esta visão do direito que poderia ser imaginada; e até defendida, pelos juristas de inspiração francesa do século XIX, tornouse inteiramente anacrônica depois de tudo o que se viu e escreveu nesta segunda metade do século XX.

11. Ainda que seja correta a proposição de Chiovenda de que o processo não pode resolver-se em prejuízo de quem tenha razão, devendo, ao contrário, dar-lhe tudo o que o litigante vitorioso tiver direito, resta saber, em cada caso concreto, o que realmente ele teria direito de conseguir, a custa da outra parte, se levarmos em conta a circunstância óbvia de que a sucumbência nem sempre - até poder-se-ia dizer apenas raramente - é fruto da má fé, ou da temeridade do litigante que sucumbe.

$\mathrm{O}$ que comumente acontece - a grande e universal regra que preside a sorte dos litigantes, na cena judiciária - é estarem ambas as partes, ao ter início a demanda, na honesta e sincera conviç̧ão de que lograrão convencer o julgador de que o direito lhes ampara, porque naturalmente a qualquer das partes socorrem circunstâncias e argumentos perfeitamente legítimos e convincentes que, aceitos pelo julgador, poderão determinar um julgmento favorável.

Em nossa prática judiciária, notória pela morosidade com que se desenvolvem as demandas, não é raro ocorrer que a sucumbência tenha origem numa mudança da jurisprudência predominante nos tribunais, tornando inaceitáveis os fundamentos seja da ação ou da defesa que, ao tempo em que os litigantes as produziram no processo, eram perfeitamente admitidos como legítimos e conformes à lei. 
12. O argumento de Chiovenda poderia prestar-se ainda a um questionamento mais radical, se tivessemos em conta que a necessidade do processo não nasce nunca do fato da resistência do vencido, mas a proibição, imposta pelo Estado, de que o titular do direito o realize privadamente. Pudesse o litigante que tem razão exercê-la privadamente, o custo do processo teria desapare cido. Logo, deveria caber ao Estado a obrigação de indenizar as despesas efetuadas pelo vencedor.

Este argumento adicional, ao que supomos, reforça, ainda mais, a idéia de que o sistema de responsabilidade objetiva assenta-se na culpa presumida do vencido, exasperando e não contrapondo-se, como se poderia supor, ao sistema da causalidade.

13. Pois bem, admita-se que não se deva atribuir ao Estado o encargo pelas despesas processuais. Neste caso, por que não se deveria reparti-lo por ambos os litigantes, reservando o critério da sucumbência apenas para as hipóteses em que se comprovasse, em cada caso concreto, a culpa do vencido pela instauração do litígio? Tanto o vencido quanto o vencedor servem-se do processo salvo prova em contrário (!) - na sincer convicção de que poderão convencer o julgador de que o direito lhes ampara e que, ao final da luta judiciária, acabarão sagrando-se vencedores.

$\mathrm{Na}$ verdade, servem-se do processo por uma contingência inelutável, pressupost como condição elementar da própria convivência social harmônica e pacífica, sendo natural que os custos desse serviço público sejam repartidos entre seus usuários, como o são as demais despesas que o Estado cobre com suas receitas fiscais.

Carnelutti percebeu muito bem a lógica que se oculta sob o sistema da responsabilidade objetiva, ao dizer que fora necessário desestimular a procura do serviço jurisdicional, pondo um freio mais enérgico que reduzisse o número de litígios, criando-se na prática um gravame econômico a tal ponto oneroso para o sucumbente que evitasse as lides temerárias ou improváveis. Ora, a representado pelo aludido terreno. Sucede que o testamento, lavrado em escritura pública, ressente-se de um pequeno vício formal, pois embora o tabelião portasse por $f$ a declaração de haverem as testemunhas estado presentes a toda a cerimônia de lavra tura do testamento, não inseriu no instrumento a declaração de havê-lo lido n presença do testador e das testemunhas (art. 1.632 combinado com o art. 1.634 do Código Civil).

Em tais circunstâncias, imóveis idêntico terão diferentes valores de mercado, pois possibilidade de um litígio futuro reduzira o valor comercial do terreno havido por sucessão testamentária. Se atribuirmos ao primeiro o valor 100 , o outro provavelmente não alcançará, no mercado, mais do que 80 .

Seu proprietário herdou, na verdade, um terreno que vale 80 . Como e à custa de quem ele poderá transformar esse imóvel elevando para 100 seu valor de comércio Segundo nosso Código e a doutrina da responsabilidade objetiva, ele disporá de uma fórmula perfeitamente legítima para acrescer a seu imóvel o défice de valor que lhe faltava. Basta promover contra os demais sucessores uma ação visando ao reconhecimento da plena validade do testamento, ou então, em demanda pelos demais herdeiros promovida para anulá-lo, vindo a obter sentença favorável, de modo que sua propriedade torne-se imune ao novos ataques. Os vencidos nessas ações ter-lhe-ão conferido os vinte por cento de valor que lhe faltava e que, na realidade, ele nunca tivera.

Teria acontecido, entretanto, que a sucumbência a que foram submetidos os demais herdeiros não se originara, de modo algum, em conduta culposa ou em qualquer outra forma de resistência injustificada ao direito do vencedor, mas ao contrário estavam eles, tanto quanto o legatário, escudados em bons argumentos legais e em fartos precedentes jurisprudenciais, que poderiam dar-lhes a vitória. A questão jurídica era, em si mesma, controvertida e duvidosa, como acontece na generalidade dos casos apreciados pelos tribunais.
Recoloca-se, portanto, o problema de Chiovenda: - o processo não deve reverter em dano do que tem razão, de modo que o titular do direito judicialmente reconhecido receba, através da sentença, tudo o que lhe for devido. Contudo, em nosso exemplo, qual haveria de ser o "tudo" a que o legatário teria direito, por ser devido pelos sucumbentes? Simplificando a questão: o legatário teria direito aos vinte por cento de segurança jurídica que a sentença lhe concedera, de modo a tornar sua propriedade inexpugnável? Ou o aumento de valor obtido com a sentença fora na verdade um acréscimo patrimonial originariamente conseguido a custa dos vencidos?

Para responder negativamente a esta in dagação, sustentando o princípio da responsabilidade objetiva, teríamos de pressupor o velho dogma iluminista que permeia nossas instituições processuais, afirmando a transparência e inquestionabilidade de todos os direitos estabelecidos pelo ordenamento jurídico, demonstrando que a sentença que proclamou a validade do testamento apenas declarou um direito já inteiramente preexistente ao processo e que, na verdade, o legatário tivera sempre um bem cujo valor de mercado fora, desde o princípio, 100 e não 80 por nós tidos aparentemente como verdadeiros.

Eis a ligadura entre o princípio da responsabilidade objetiva pelas despesas da causa e o fundamento primordial, que a todos os demais se superpõe, da jurisdição como declaração de direitos. rigorosamente idênticos quer por sua conticaracterísticas físicas. São dois terrenos, situados um ao lado do outro, possuindo ambos as mesmas dimensões e idênticas peculiaridades físicas. Um deles pertence ao pra e venda e correspondente registro imobiliário perfeitamente regulares e sem qualquer mácula que pudesse tornar a propriedade duvidosa ou controvertida.

$\mathrm{O}$ outro terreno pertence a $\mathrm{Y}$ que o recebeu por testamento, na condição de herdeiro legítimo aquinhoado com um legado 